\title{
КЛЮЧЕВЫЕ ПОКАЗАТЕЛИ ЭФФЕКТИВНОСТИ ДЕЯТЕЛЬНОСТИ УПОЛНОМОЧЕННОГО ПО ПРАВАМ РЕБЕНКА В РОССИЙСКОЙ ФЕДЕРАЦИИ (на примере Дальневосточного федерального округа)
} эффективности деятельности Уполномоченного по правам ребенка в Российской Федерации (на примере Дальневосточного федерального округа). На основе анализа нормативно-правовых актов, регулирующих деятельность Уполномоченных по правам ребенка, была определена система ключевых показателей их деятельности. Ключевые показатели эфрфективности деятельности важны как при оценке собственной работы, так и в сравнении с деятельностью других Уполномоченных субъектов Российской Федерации. Поэтому, при определении ключевых показателей эфрфективности учтены только те, которые определяют деятельность, характерную для всех Уполномоченных по правам ребенка. В процессе исследования применялись теоретический, общефилософрские методы (диалектика, системный метод, анализ, синтез, аналогия, дедукция, наблюдение, моделирование), традиционно правовые методы (формально-логический), а также методы, используемые при поведении социологических исследований. Научная новизна исследования состоит в том, что на основе анализа нормативно-правовых актов субъектов Российской Федерации Дальневосточного федерального округа, регулирующих деятельность Уполномоченных, впервые предложены ключевые показатели эффективности деятельности Уполномоченных по правам ребенка. Предложенная система ключевых показателей эффективности деятельности Уполномоченного не носит исчерпывающего характера, вместе с тем, представляет собой необходимый инструмент, способствующий эффективной работе Уполномоченных.

Ключевые слова: Уполномоченный, Ребенок, Дети, Родители, Забота, Защита, Критерий, Эфрективность, Показатель, Полиция.

Review. The article focuses on the activities of the Children's Rights Commissioner in Far Eastern okrug of the Russian Federation. The author analyzes normative legal acts regulating the work of Children's Rights Commissioners, and defines the system of key rates of their activities. These rates are important for the assessment of their own work and for the comparison with the activities of Commissioners of other regions. Therefore, the author takes into consideration only the rates, common for all Commissioners. The author applies the theoretical and general philosophical methods (dialectics, the systems method, analysis, synthesis, analogy, deduction, observation, modeling), the traditional legal methods (formal logical) and sociological methods. The novelty of the research consists in the development of key effectiveness rates for the activities of the Children's Rights Commissioner on the base of the analysis of normative-legal acts of Far Eastern okrug of the Russian Federation. This system of rates is not complete, but it is a necessary instrument of Commissioners' work improvement.

Keywords: Criterion, Protection, Care, Parents, Children, Child, Commissioner, effectiveness, rate, Police.

$\Pi$ ри конституционно-правовом регулировании статуса ребенка, важно не только закрепление прав несовершеннолетних, но и создание эффективной системы гарантий реализации, защиты и восстановления нарушенных прав. Уполномоченный по правам ребенка (далее - Уполномоченный), как на федеральном, так и на региональном уровнях, представляет собой важнейший институт этой системы. Президентом Российской Федерации В.В. Путиным на встрече с членами Совета при Президенте по развитию гражданского общества и правам человека, уполномоченными по правам человека, уполномоченными по правам ребенка, уполномоченными по защите прав предпринимателей 5 декабря 2014 года дана высокая оценка работы как федерального, так и региональных уполномоченных по правам ребенка. Несмотря на такую оценку, вопрос об эффективности деятельности Уполномоченных является актуальным, что обусловлено современной государственной политикой, направленной на развитие и защиту института семьи. Справедливости ради отметим, что эффективность и система ключевых показателей деятельности органов власти является дискуссионной в научном сообществе.

Цель исследования состоит в определении ключевых показателей эффективности деятельности Уполномоченных в субъектах Российской Федерации Дальневосточного федерального округа. Для этого необходимо: выбрать ключевые показатели эффективности из всех возможных, которые будут понятны и просты в использовании; определить источник достоверности данных, на которых они могут основываться. Ключевые показатели 


\section{Административное и муниципальное право 10 (94) • 2015}

эффективности деятельности важны как при оценке собственной работы, так и в сравнении с деятельностью других Уполномоченных субъектов Российской Федерации. Поэтому, при определении ключевых показателей эффективности будут учитываться только те, которые определяют деятельность, характерную для всех Уполномоченных.

Правовой базой для разработки системы ключевых показателей эффективности деятельности Уполномоченных являются нормативно-правовые акты субъектов Российской Федерации Дальневосточного федерального округа, регулирующие деятельность Уполномоченных по правам ребенка [1].

Показатели эффективности, в первую очередь, зависят от цели деятельности Уполномоченных. Указанные нормативно-правовые акты, регулирующие деятельность Уполномоченных, устанавливают, что должность учреждается в целях государственной защиты, реализации и обеспечения прав и законных интересов ребёнка на территории соответствующего субъекта, их соблюдения и уважения государственными органами, органами местного самоуправления, организациями и должностными лицами. Деятельность Уполномоченного дополняет существующие средства защиты прав, свобод и законных интересов ребенка, не отменяет и не влечет пересмотра компетенции органов государственной власти, органов местного самоуправления, их должностных лиц, обеспечивающих защиту и восстановление нарушенных прав, свобод и законных интересов ребенка рассматриваемых субъектов. Важнейшими задачами Уполномоченного являются: обеспечение гарантий государственной защиты прав и законных интересов ребенка, содействие в реализации прав и законных интересов ребенка и восстановлении нарушенных прав ребенка. В ряде субъектов Российской Федерации (Республика Саха (Якутия) (ч.2 ст.3), Хабаровский край (ч.5 ст.11), Амурская область (п.5) защита прав, свобод и законных интересов детей-сирот, детей, оставшихся без попечения родителей, и иных детей, находящихся в трудной жизненной ситуации, является приоритетным направлением деятельности Уполномоченного [2]. Сразу отметим, что целевая группа потребителей государственных услуг Уполномоченного представляет собой несовершеннолетних лиц, нуждающихся в содействии реализации законных интересов, в восстановлении нарушенных их прав. Не имеет значения, кто из субъектов права обратился в защиту прав и законных интересов несовершеннолетних, сам несовершеннолетний или законный представитель, третье лицо, должностное лицо органов государственной власти, органов местного самоуправления, представитель общественной организации. Значение имеет нарушенное право ребенка или потребность в получении содействия в реализации и защите прав и законных интересов несовершеннолетнего.

Указанные цели и задачи определяют направления деятельности Уполномоченного, выраженные, в свою очередь, в компетенции и полномочиях.

Правозащитная деятельность Уполномоченного является одной из основополагающих, осуществляемая посредством приема граждан, рассмотрения обращений, касающихся нарушения прав, свобод и законных интересов ребенка, и жалоб на решения или действия (бездействие) органов государственной власти, органов местного самоуправления, организаций и предприятий рассматриваемых субъектов, их должностных лиц, нарушающих права, свободы и законные интересы ребенка. Важным полномочием правозащитной деятельности Уполномоченного является его возможность участия в судебном процессе. Тем не менее, не все Уполномоченные наделены такой юридической возможностью. Уполномоченный в Республике Саха (Якутия) (п.п. г, д. ч.2 ст. 9), в Еврейской автономной области (ч.7 ст.13) наделен правом обратиться в суд с заявлением о защите нарушенных прав, свобод и законных интересов ребенка в случаях, предусмотренных законом, либо предлагать обратиться в суд с подобным заявлением компетентным органам; а также принимать участие лично либо через своего представителя в установленных законом случаях и формах в судебных процессах с целью защиты и восстановления нарушенных прав, свобод и законных интересов ребенка [3].

Поскольку правом обратиться в суд, а также принять участие лично либо через своего представителя в судебных процессах с целью защиты и восстановления нарушенных прав, свобод и законных интересов ребенка наделены не все Уполномоченные, то они не могут быть учтены при определении ключевых критериев эффективности. Следовательно, критериями эффективности будут являться:1) количество жалоб, результатом рассмотрения которых явилось содействие в восстановлении нарушенного права к общему количеству поступивших к Уполномоченному; 2) количество рассмотренных жалоб без нарушения норм действующего законодательства к общему количеству обращений.

Содействуя реализации прав и законных интересов ребенка, Уполномоченный в рассматриваемых субъектах осуществляет мониторинг соблюдения прав и законных интересов ребенка. Мониторинг соблюдения прав и интересов ребенка предполагает системное исследование с целью выявить нарушения и, как результат, принять меры, направленные на восстановление нарушен- 
ных прав детей. Следовательно, задачами мониторинга являются: сбор, анализ данных о правах ребенка в различных сферах его жизнедеятельности; выявление фактов нарушения прав детей и анализ причин и факторов, способствовавших нарушению; принятие мер, направленных на восстановление нарушенных прав и изменение ситуации в дальнейшем. Сбор данных может осуществляться различными способами, включая рабочие поездки Уполномоченного в детские учреждения.

Критерием эффективности будет являться отношение количества проведенных мониторингов к планируемым. Практика показывает, что оптимально проводить мониторинг один раз в квартал в течение года (март, июнь, сентябрь, декабрь). Количество рабочих инспекций не менее четырех раз в месяц с посещением не менее двух учреждений за одну инспекцию по отношению к планируемым.

Существенным является право Уполномоченного вносить предложения руководству соответствующих субъектов Российской Федерации по совершенствованию регионального законодательства о правах и законных интересах ребенка, по разработке концепции семейной политики, защиты прав и законных интересов ребенка. В Республике Саха (Якутия) (п. к ч. 2 ст.9), в Хабаровском крае (ч.1 ст.13), в Еврейской автономной области (ч.9 ст.13), в Сахалинской области (п.4.1.9) предусмотрено участие Уполномоченного в разработке нормативных правовых актов соответствующего субъекта, затрагивающих права, свободы и законные интересы ребенка [4]. Кроме этого, в Еврейской автономной области Уполномоченный реализует право законодательной инициативы в Законодательном Собрании области по вопросам, отнесенным к его ведению, участвует в работе Законодательного Собрания области и его комитетов, в заседаниях правительства области при рассмотрении вопросов, касающихся обеспечения прав, свобод и законных интересов ребенка (ч.9 ст.13) [5].

Ключевым показателем эффективности деятельности Уполномоченного следует определить количество принятых руководством соответствующего субъекта Российской Федерации предложений по совершенствованию регионального законодательства о правах и законных интересах ребенка, по разработке концепции семейной политики, защиты прав и законных интересов ребенка по отношению к количеству внесенных.

Эффективность работы уполномоченного во многом зависит от уровня взаимодействия его с органами власти, институтами гражданского общества. Формы работы могут быть разные, включая, участие в межведомственных комиссиях, в работе коллегий федеральных служб, в том числе на основании заключенных соглашений с органами государственной власти; участие в научно-практических конференциях, круглых столах, прессконференциях.

Ключевым показателем эффективности будет количество принятых рекомендаций Уполномоченного при его участии в работе межведомственных комиссий, коллегиях федеральных служб, научно-практических конференциях, круглых столах по отношению к предложенным рекомендациям.

Информирование Уполномоченным общественности о состоянии соблюдения и защиты прав и законных интересов ребенка, пропаганда положений Конвенции о правах ребенка, одобренной Генеральной Ассамблеей ООН 20 ноября 1989 г.; поддержка гражданских инициатив в сфере защиты прав законных интересов ребенка является необходимой составляющей в деятельности. Данная работа имеет большое значение, в том числе в формировании правовой культуры граждан, поскольку содействует обеспечению прав и законных интересов несовершеннолетних.

Информирование общественности возможно через официальный сайт Уполномоченного, взаимодействие со средствами массовой информации, посредством выступлений на радио, телевидении, интервью печатным периодическим изданиям, пресс-конференции по проблемам защиты прав несовершеннолетних и т.д.

Ключевыми показателями эффективности деятельности Уполномоченного в рамках данного направления деятельности будут: количество выступлений, публикаций на радио, телевидении, интервью печатным периодическим изданиям, пресс-конференции по проблемным вопросам защиты прав несовершеннолетних не менее одного раза в месяц по отношению к планированным в течение года.

Важными в работе Уполномоченного являются подготовка и публикация ежегодного Доклада Уполномоченного целями которого являются: 1) характеристика основных направлений деятельности Уполномоченного; 2) анализ соблюдения прав и законных интересов, а также выявление фактов и причин нарушения прав и законных интересов детей в субъекте Российской Федерации; 3) привлечение внимания органов государственной власти, местного самоуправления, а также институтов гражданского общества к проблемам соблюдения прав и законных интересов ребенка. Доклад должен отразить всю работу Уполномоченного за год в деле защиты прав и законных интересов несовершеннолетних с учетом ключевых показателей эффективности его деятельности.

Можно выделить следующие источники данных, на которых должны основываться показатели эффективности деятельности Уполномоченного: 


\section{Административное и муниципальное право $10(94) \cdot 2015$}

письменные и устные обращения граждан; факты нарушения прав и законных интересов несовершеннолетних в результате мониторинга; нормативные правовые акты в сфере семейной политики, принятые с учетом рекомендаций и предложений Уполномоченного; официальные статистические данные; информация органов государственной власти, а также органов местного самоуправления; сведения, полученные уполномоченным в ходе участия в совещаниях, встречах, конференциях, «круглых столах», на которых обсуждались вопросы защиты прав и законных интересов детей, материалы выступлений на радио, телевидении, публикаций в печатных периодических изданиях, пресс-конференций по проблемным вопросам защиты прав несовершеннолетних.

Таким образом, ключевыми показателями эффективности деятельности Уполномоченного будут являться: 1) количество жалоб, результатом рассмотрения которых явилось содействие в восстановлении нарушенного права к общему количеству поступивших к Уполномоченному; 2) количество рассмотренных жалоб без нарушения норм действующего законодательства к общему количеству обращений; 3) отношение количества проведенных мониторингов к планируемым; 4) количество рабочих инспекций не менее четырех раз в месяц с посещением не менее двух учреждений за одну инспекцию по отношению к планируемым; 5) количество принятых руководством соответствующего субъекта Российской Федерации предложений по совершенствованию регионального законодательства о правах и законных интересах ребенка, по разработке концепции семейной политики, защиты прав и законных интересов ребенка по отношению к количеству внесенных; 6) количество принятых рекомендаций Уполномоченного при его участии в работе межведомственных комиссий, коллегиях федеральных служб, научно- практических конференциях, круглых столах по отношению к предложенным рекомендациям; 7) количество выступлений на радио, телевидении, публикаций в печатных периодических изданиях, пресс-конференций по проблемным вопросам защиты прав несовершеннолетних из расчета не менее одного раза в месяц по отношению к планированным в течение года.

Показатель эффективности деятельности Уполномоченного можно рассчитать по формуле:

$$
\mathrm{P}_{3}=\frac{\mathrm{P}_{1}+\mathrm{P}_{2}+\mathrm{P}_{3}+\mathrm{P}_{4}}{\mathrm{n}} \text {, где }
$$
баллах;

$\mathrm{P}_{\text {э }}$ показатель эффективности, выраженный в

P1; P2; P3; P4; Pn - ключевые показатели эффективности;

n - количество ключевых показателей.

Например, показатель эффективности рассмотрения жалоб можно выразить отношением:

$$
\mathrm{P}_{1}=\frac{\mathrm{G}}{\mathrm{O}} \times 10 \text {, где }
$$
жалоб;

$\mathrm{P}_{1}$ - показатель эффективности рассмотрения

G - количество жалоб, результатом рассмотрения которых явилось содействие в восстановлении нарушенного права;

0 - общее количество обращений, поступивших к Уполномоченному;

10 - максимальное количество баллов (для всех показателей).

Аналогично рассчитываются остальные показатели эффективности.

В целом, предложенная система ключевых показателей эффективности деятельности Уполномоченного представляет собой лишь необходимый инструмент, способствующий эффективной работе Уполномоченных. Важно выявить факторы, влияющие на результат деятельности Уполномоченного по ключевым показателям.

\section{Библиография:}

1. Закон Республики Саха (Якутия) «Об Уполномоченном по правам ребенка в Республике Саха (Якутия)» от 5 февраля 2003 года 4-3 № 6-II // Якутские ведомости. 2003. 20 февраля; Закон Хабаровского Края «Об Уполномоченном по правам ребенка в Хабаровском крае» 23 ноября 2011 № 135 (в ред. от 28 марта 2012 № 179) // Собрание законодательства Хабаровского края. 2011. № 12(113) (ч.1); Закон Еврейской автономной области «Об Уполномоченном по правам ребенка в Еврейской автономной области» от 23 декабря 2011 № 05-03 // Биробиджанская звезда. 2011. 28 декабря; Постановление Губернатора Приморского края «Об утверждении Положения об уполномоченном при Губернаторе Приморского края по правам ребенка» от 21 декабря 2010 № 109 -пг (с изм. от 10 февраля 2012 №6-пг) // Приморская газета. 2010. 29 декабря; Постановление Губернатора Амурской области «Об утверждении положения об уполномоченном по правам ребенка в Амурской области» от 30 января 2010 № 26 (ред. от 13 июля 2010 № 248) // Амурская правда. 2010. 30 января; Указ Губернатора Сахалинской области «Об утверждении положения об Уполномоченном при Губернаторе Сахалинской области по правам ребенка» от 13 января 2011 № 1 // Губернские ведомости.2011. 22 января.

2. Закон Республики Саха (Якутия) «Об Уполномоченном по правам ребенка в Республике Саха (Якутия)» от 5 февраля 2003 года 4-3 № 6-II // Якутские ведомости. 2003. 20 февраля; Закон Хабаровского Края «Об Уполномоченном по правам ребенка в Хабаровском крае» 23 ноября 2011 № 135 (в ред. от 28 марта 2012 № 179) // Собрание законодательства Хабаровского края. 2011. № 12(113) (ч.1); Постановление Губернатора Амурской области «Об 
утверждении положения об уполномоченном по правам ребенка в Амурской области» от 30 января 2010 № 26 (ред. от 13 июля 2010 № 248) // Амурская правда. 2010. 30 января.

3. Закон Республики Саха (Якутия) «Об Уполномоченном по правам ребенка в Республике Саха (Якутия)» от 5 февраля 2003 года 4-3 № 6-II // Якутские ведомости. 2003. 20 февраля; Закон Еврейской автономной области «Об Уполномоченном по правам ребенка в Еврейской автономной области» от 23 декабря 2011 № 05-03 // Биробиджанская звезда. 2011. 28 декабря.

4. Закон Республики Саха (Якутия) «Об Уполномоченном по правам ребенка в Республике Саха (Якутия)» от 5 февраля 2003 года 4-3 № 6-II // Якутские ведомости. 2003. 20 февраля; Закон Хабаровского Края «Об Уполномоченном по правам ребенка в Хабаровском крае» 23 ноября 2011 № 135 (в ред. от 28 марта 2012 № 179) // Собрание законодательства Хабаровского края. 2011. № 12(113) (ч.1); Закон Еврейской автономной области «Об Уполномоченном по правам ребенка в Еврейской автономной области» от 23 декабря 2011 № 05-03 // Биробиджанская звезда. 2011. 28 декабря; Указ Губернатора Сахалинской области «Об утверждении положения об Уполномоченном при Губернаторе Сахалинской области по правам ребенка» от 13 января 2011 № 1 // Губернские ведомости. 2011. 22 января.

5. Закон Еврейской автономной области «Об Уполномоченном по правам ребенка в Еврейской автономной области» от 23 декабря 2011 № 05-03 // Биробиджанская звезда. 2011. 28 декабря.

6. Карасев Р.Е. Судебная защита: понятие, значение, место в системе защиты прав и свобод человека и гражданина // Право и политика. - 2013. - 11. - C. 1511 - 1519. DOI: 10.7256/1811-9018.2013.11.10147.

7. Куракин А.В., Костенников М.В. Административно-правовое противодействие коррупции в системе государственной службы и в деятельности сотрудников полиции Российской Федерации и зарубежных государств // Полицейская и следственная деятельность. - 2013. - 1. - С. 65 - 83. DOI: 10.7256/2409-7810.2013.1.735. URL: http://www.e-notabene.ru/pm/article_735.html

8. Чвякин В.А. Анализ агрессивных свойств личности подростка и их использование в профилактической деятельности полиции // Полицейская и следственная деятельность. - 2014. - 2. - C. 30 - 51. DOI: 10.7256/24097810.2014.2.13954. URL: http://www.e-notabene.ru/pm/article_13954.html

9. Габиева С.М., Керамова С.Н. К вопросу о конституционно-правовой защите прав детей в Российской Федерации // Право и политика. - 2013. - 12. - С. 1611 - 1613. DOI: 10.7256/1811-9018.2013.12.9800.

10. Куракин А.В., Костенников М.В. Принципы организации и деятельности российской полиции // Полицейская и следственная деятельность. - 2013. - 2. - C. 22 - 49. DOI: 10.7256/2409-7810.2013.2.799. URL: http://www.enotabene.ru/pm/article_799.html

\section{References (transliterated):}

1. Zakon Respubliki Sakha (Yakutiya) «Ob Upolnomochennom po pravam rebenka v Respublike Sakha (Yakutiya)» ot 5 fevralya 2003 goda 4-Z № 6-II // Yakutskie vedomosti. 2003. 20 fevralya; Zakon Khabarovskogo Kraya «Ob Upolnomochennom po pravam rebenka v Khabarovskom krae» 23 noyabrya 2011 № 135 (v red. ot 28 marta 2012 № 179) // Sobranie zakonodatel'stva Khabarovskogo kraya. 2011. № 12(113) (ch.1); Zakon Evreiskoi avtonomnoi oblasti «Ob Upolnomochennom po pravam rebenka v Evreiskoi avtonomnoi oblasti» ot 23 dekabrya 2011 № 05-OZ // Birobidzhanskaya zvezda. 2011. 28 dekabrya; Postanovlenie Gubernatora Primorskogo kraya «Ob utverzhdenii Polozheniya ob upolnomochennom pri Gubernatore Primorskogo kraya po pravam rebenka» ot 21 dekabrya 2010 № 109 pg (s izm. ot 10 fevralya 2012 №6-pg) // Primorskaya gazeta. 2010. 29 dekabrya; Postanovlenie Gubernatora Amurskoi oblasti «Ob utverzhdenii polozheniya ob upolnomochennom po pravam rebenka v Amurskoi oblasti» ot 30 yanvarya 2010 № 26 (red. ot 13 iyulya 2010 № 248) // Amurskaya pravda. 2010. 30 yanvarya; Ukaz Gubernatora Sakhalinskoi oblasti «Ob utverzhdenii polozheniya ob Upolnomochennom pri Gubernatore Sakhalinskoi oblasti po pravam rebenka» ot 13 yanvarya 2011 № 1 // Gubernskie vedomosti.2011. 22 yanvarya.

2. Zakon Respubliki Sakha (Yakutiya) «Ob Upolnomochennom po pravam rebenka v Respublike Sakha (Yakutiya)» ot 5 fevralya 2003 goda 4-Z № 6-II // Yakutskie vedomosti. 2003. 20 fevralya; Zakon Khabarovskogo Kraya «Ob Upolnomochennom po pravam rebenka v Khabarovskom krae» 23 noyabrya 2011 № 135 (v red. ot 28 marta 2012 № 179) // Sobranie zakonodatel'stva Khabarovskogo kraya. 2011. № 12(113) (ch.1); Postanovlenie Gubernatora Amurskoi oblasti «Ob utverzhdenii polozheniya ob upolnomochennom po pravam rebenka v Amurskoi oblasti» ot 30 yanvarya 2010 № 26 (red. ot 13 iyulya 2010 № 248) // Amurskaya pravda. 2010. 30 yanvarya.

3. Zakon Respubliki Sakha (Yakutiya) «Ob Upolnomochennom po pravam rebenka v Respublike Sakha (Yakutiya)» ot 5 fevralya 2003 goda 4-Z № 6-II // Yakutskie vedomosti. 2003. 20 fevralya; Zakon Evreiskoi avtonomnoi oblasti «Ob Upolnomochennom po pravam rebenka v Evreiskoi avtonomnoi oblasti» ot 23 dekabrya 2011 № 05-0Z // Birobidzhanskaya zvezda. 2011. 28 dekabrya.

4. Zakon Respubliki Sakha (Yakutiya) «Ob Upolnomochennom po pravam rebenka v Respublike Sakha (Yakutiya)» ot 5 fevralya 2003 goda 4-Z № 6-II // Yakutskie vedomosti. 2003. 20 fevralya; Zakon Khabarovskogo Kraya «Ob Upolnomochennom po pravam rebenka v Khabarovskom krae» 23 noyabrya 2011 № 135 (v red. ot 28 marta 2012 № 179) // Sobranie zakonodatel'stva Khabarovskogo kraya. 2011. № 12(113) (ch.1); Zakon Evreiskoi avtonomnoi oblasti «Ob Upolnomochennom po pravam rebenka v Evreiskoi avtonomnoi oblasti» ot 23 dekabrya 2011 № 05-0Z // Birobidzhanskaya zvezda. 2011. 28 dekabrya; Ukaz Gubernatora Sakhalinskoi oblasti «Ob utverzhdenii polozheniya ob Upolnomochennom pri Gubernatore Sakhalinskoi oblasti po pravam rebenka» ot 13 yanvarya 2011 № 1 // Gubernskie vedomosti. 2011. 22 yanvarya.

5. Zakon Evreiskoi avtonomnoi oblasti «Ob Upolnomochennom po pravam rebenka v Evreiskoi avtonomnoi oblasti» ot 23 dekabrya 2011 № 05-OZ // Birobidzhanskaya zvezda. 2011. 28 dekabrya. 


\section{Административное и муниципальное право $10(94) \cdot 2015$}

6. Karasev R.E. Sudebnaya zashchita: ponyatie, znachenie, mesto v sisteme zashchity prav i svobod cheloveka i grazhdanina // Pravo i politika. - 2013. - 11. - C. 1511 - 1519. DOI: 10.7256/1811-9018.2013.11.10147.

7. Kurakin A.V., Kostennikov M.V. Administrativno-pravovoe protivodeistvie korruptsii v sisteme gosudarstvennoi sluzhby i v deyatel'nosti sotrudnikov politsii Rossiiskoi Federatsii i zarubezhnykh gosudarstv // Politseiskaya i sledstvennaya deyatel'nost'. - 2013. - 1. - C. 65 - 83. DOI: 10.7256/2409-7810.2013.1.735. URL: http://www.e-notabene.ru/pm/ article_735.html

8. Chvyakin V.A. Analiz agressivnykh svoistv lichnosti podrostka i ikh ispol'zovanie v profilakticheskoi deyatel'nosti politsii // Politseiskaya i sledstvennaya deyatel'nost'. - 2014. - 2. - C. 30 - 51. DOI: 10.7256/2409-7810.2014.2.13954. URL: http://www.e-notabene.ru/pm/article_13954.html

9. Gabieva S.M., Keramova S.N. K voprosu o konstitutsionno-pravovoi zashchite prav detei v Rossiiskoi Federatsii // Pravo i politika. - 2013. - 12. - C. 1611 - 1613. DOI: 10.7256/1811-9018.2013.12.9800.

10. Kurakin A.V., Kostennikov M.V. Printsipy organizatsii i deyatel'nosti rossiiskoi politsii // Politseiskaya i sledstvennaya deyatel'nost'. - 2013. - 2. - C. 22 - 49. DOI: 10.7256/2409-7810.2013.2.799. URL: http://www.e-notabene.ru/pm/ article_799.html 